\title{
A INVESTIGAÇÃO DA LÍNGUA PORTUGUESA: O AMMOR À PESQUISA ${ }^{23}$
}

Ana Müller ${ }^{*}$

Toda ciência comparada com a realidade, é primitiva e infantil - $e$, no entanto, é a coisa mais preciosa que temos.

Einstein (1879-1955)

Durante grande parte do período em que foi professor visitante no Departamento de Lingüística da USP (agosto de 1999 - final de 2000), Carlos Franchi dividiu uma sala com Esmeralda Negrão e comigo. A cada quinze dias, às terças-feiras, ele participava dos Seminários de Teoria Gramatical que ocorriam pela manhã. Nossas terças à tarde então consistiam de longas conversas, às vezes só comigo, às vezes com a Esmeralda e comigo e, às vezes com a participação de outras pessoas. Conversávamos sobre Lingüística, às vezes sobre política acadêmica,e, algumas vezes, sobre o papel da Ciência e da Pesquisa. Escrever este artigo me fez relembrar muitas de nossas conversas e penso que Franchi concordaria com grande parte das idéias que exponho aqui.

Vou começar este artigo trazendo à tona uma tese geralmente ausente quando tratamos da investigação e do ensino da língua portuguesa - o estudo de nossa língua faz parte de um desejo maior do ser humano de compreender melhor o mundo e a si mesmo.

É claro que as pessoas estudam o português por razões bem mais concretas como, por exemplo, para escrever melhor, para falar melhor, para melhorar sua formação profissional... Muitas vezes a motivação é simplesmente a aprovação na escola. No entanto, o que eu desejo neste artigo á chamar a atenção para a dimensão mais essencial desse estudo - estudamos o português porque queremos entender como ele funciona. E queremos entender como ele funciona porque, enquanto espécie, somos curiosos. Queremos entender o mundo e a nós mesmo.

\footnotetext{
${ }^{23}$ Este texto é inspirado no artigo "Ciência e Esperança" de Carl Sagan em O Mundo Assombrado pelos Demônios. SP: Companhia das Letras, [1995] 1996.

* Professora Dra do Departamento de Lingüística FFLCH/USP
} 
O que estou argumentando é que a investigação sobre língua portuguesa e sobre as línguas em geral faz parte do projeto humano ao qual chamamos de Ciência (em um sentido mais amplo, que inclui também as Humanidades). E a Ciência é a busca organizada de um maior conhecimento sobre nós mesmos e sobre o mundo. Sendo assim, está ligada à esperança de um mundo melhor - um mundo no qual as coisas não acontecem totalmente a nossa revelia e no qual, até certo ponto, podemos escolher nosso destino enquanto indivíduos, enquanto sociedade e enquanto espécie.

Como disse acima, nós humanos somos curiosos. Ou, pelo menos, éramos curiosos quando crianças. Certamente todos nós já sentimos o encantamento de uma descoberta, de um momento de compreensão de como algo 'realmente' funciona. Um encantamento que acho que muitos poderão compartilhar comigo é o do momento em que nos damos conta de que conseguimos ler. Descobrimos a chave para algo que antes era um ministério para nós. De repente, aqueles sinais começam a fazer sentido, as peças do quebra-cabeça se encaixam. Nesse momento sentimos uma grande satisfação.

Voltando á questão da curiosidade sobre o funcionamento de nossa língua, posso citar como exemplo minha pesquisa sobre a pesquisa sobre a expressão da genericidade no português brasileiro $^{24}$. Se vocês prestarem atenção verão que muitas das sentenças que utilizamos em nosso dia-a-dia sobre padrões ou regularidades gerais, como as sentenças em $(1)-(5)$.

(1) O café é popular no Brasil

(2) As cobras são animais perigosos.

(3) Um número par é divisível por 2.

(4) Homem não chora.

(5) Professores trabalham muito.

Uma das questões que me intrigava e continua me intrigando sobre esse fenômeno é a existência de tantas formas distintas para expressar significados que, pelo menos aparentemente, parecem sinônimos. Se vocês observarem as sentenças (6) - (10) abaixo, vão poder partilhar de minhas perplexidade. Elas parecem sinônimas, não parecem? Mas então para que tantas formas? É essa a questão geral de uma de minhas pesquisas.

(6) O brasileiro gosta de futebol.

(7) Os brasileiros gostam de futebol.

\footnotetext{
${ }^{24}$ Para conhecer os resultados dessa pesquisa ver Muller 2000, 2001, 2002, entre outros.
} 
(8) Um brasileiro (sempre) gosta de futebol.

(9) Brasileiro gosta de futebol.

(10) Brasileiros gostam de futebol.

Decidi, após um exame cuidadoso dos dados e depois de realizar muitas leituras, eenfrentar o problema por partes: separei as sentenças com o sujeito definido, como (6) e (7), das sentenças com sujeito indefinido, como (8), ou com sujeito sem artigo - com sujeito 'nu' - como (9) e (10). Em outras palavras, separei as sentenças com sujeitos definidos das sentenças com sujeitos não-definidos. Entre essas últimas, deixei temporariamente de lado as sentenças com sujeito nu plural como (10), por se tratar de uma forma mais utilizada na língua escrita e eu estar interessada principalmente na linguagem coloquial oral.

Observando mais de perto o comportamento dos dois tipos de sentenças nos quais decidi me concentrar, percebi que as sentenças com o sujeito 'nu' singular, como (9), têm sempre uma interpretação genérica, ao passo que sentenças com o sujeito indefinido normalmente preferem uma interpretação específica. Vejam os exemplos em (11) e (12). Se alguém proferir (11), nossa interpretação mais imediata será a de que a pessoa deve estar ser referindo a algum restaurante específico. Normalmente não interpretamos (11) como sentença genérica. Já (12) tem apenas uma interpretação genérica - a de que todos os restaurantes italianos estão fechados hoje.

(11) Um restaurante italiano está fechado hoje.

(12) Restaurante italiano está fechado hoje.

Agora observem também a diferença entre as duas sentenças em (13) e (14), ambas com sujeito indefinido. Nossa tendência é interpretar a primeira como sendo sobre um soneto específico e a segunda como sendo sobre todo soneto, ou seja, como sentença genéricas, indenpendentemente dos fatos que venham a descrever.

(13) Um soneto tem muitas palavras terminas em 's'.

(14) Um soneto tem quatro estrofes.

(15) Soneto tem muitas palavras terminadas em 's'.

(16) Soneto tem quatro estrofes. 
Notem que o predicado ter muitas palavras terminadas em ' $s$ ' descreve uma propriedade bastante idiossincrática. Sabemos que é muito improvável que ela expresse uma propriedade inerente aos sonetos. Por outro lado, o predicado ter quatro estrofes expressa uma característica definidora dos sonetos. A intuição que emerge ao examinarmos o comportamento dessas e de outras sentenças com sujeito indefinido e com sujeito nu é a de que as primeiras, quando genéricas, tem um sabor mais de regra ou de norma, ao passo que as últimas se prestam a generalizações mais descritivas.

Vamos testar essa intuição. Imaginem que, em uma quarta-feira, você está levando um amigo americano para almoçar. Vocês param no primeiro restaurante e o prato do dia é feijoada, para no segundo e o prato do dia também é feijoada, para no terceiro, no quarto e no quinto e o mesmo acontece. Se seu amigo americano falasse português bem, ele diria (17) ou (18)?

(17) Um brasileiro come feijoada hoje.

(18) Brasileiro come feijoada hoje.

Sem dúvida (18) seria a sentença apropriada neste contexto. Vejam que se trata de um contexto em que o falante está verbalizando uma generalização a partir de uma série de ocorrências. Ou seja ele está efetuando a descrição de um padrão percebido - uma generalização indutiva.

Agora imagine um outro contexto. Hoje é quarta-feira e seu amigo americano convida você para comer sushi. Você indignado, responde proferindo (19). Aqui o sujeito indefinido cai bem com uma interpretação genérica, pois estamos expressando uma espécie de norma: Um verdadeiro brasileiro come feijoada às quartas feiras.

(19) Hoje não é dia de sushi! Um brasileiro come feijoada hoje!

Bem, a essa altura, eu já descobri algo sobre o funcionamento das sentenças genéricas. As sentenças com sujeito indefinido servem para expressar 'regras' ou 'normas'. Já as sentenças com o sujeito nu servem para expressar generalizações descritivas ou indutivas. De uma outra perspectiva, podemos dizer que as sentenças genéricas com sujeito indefinido expressam generalizações sobre situações prototípicas ou situações-modelo, ao passo que sentenças genéricas com sujeitos nus expressam generalizações sobre situações reais. 
Essa descoberta - como todas as descobertas - me coloca diante de uma nova questão: quais, dentre as características lexicais e estruturais de cada um dos dois tipos de sentenças, torna as sentenças com indefinido mais apropriadas para expressar generalizações normativas e as sentenças com sujeito nu mais apropriadas para expressar generalizações descritivas? Pares de sentenças como os que vimos acima e que repito abaixo em (20) - (29) diferem entre si apenas pela forma de seu sujeito. É aí, portanto, que devemos buscar a explicação para o comportamento diferente dos dois tipos de sentenças.

Um brasileiro (sempre) gosta de futebol.

Brasileiro gosta de futebol.

Um restaurante italiano está fechado hoje. Restaurante italiano está fechado hoje.

Um soneto tem muitas palavras terminadas em ' $s$ ' Soneto tem muitas palavras terminadas em 's'. Um soneto tem quatro estrofes. Soneto tem quatro estrofes.

Um brasileiro come feijoada hoje. Brasileiro come feijoada hoje.

Sintagmas indefinidos como um brasileiro, um italiano e um soneto realizam a operação semântica de selecionar dentro de um certo contexto um indivíduo ou uma entidade qualquer. Assim, as generalizações efetuadas a partir desses sintagmas são feitas selecionando-se uma entidade de cada vez. Os padrões que podem emergir desse processo tem de resultar propriedades bastante essenciais da entidade sobre a qual se está generalizando, pois eles devem se repetir para cada entidade. Daí a propriedade de que sentenças genéricas com sujeitos indefinidos expressam generalizações mais prototípicas, mais essenciais.

Sintagmas nus como brasileiro, restaurante italiano e soneto, por outro lado, realizam a operação de selecionar um número indefinido de indivíduos ou entidades. Assim, as generalizações efetuadas a partir desses sintagmas são feitas selecionando-se um grupo de entidades de cada vez. Os padrões que podem emergir desse processo são mais variados e podem ser acidentais. Daí a característica das sentenças com sujeitos nus de expressar generalizações mais contingentes, mais acidentais ${ }^{25}$.

Tenho agora uma resposta à questão colocada mais acima. A sensação que esse e as outras descobertas sobre o assunto me trazem é de satisfação. É claro que existe muito mais

\footnotetext{
${ }^{25}$ Para uma exposição mais detalhada e técnica deste trabalho, ver Muller no prelo.
} 
a ser compreendido, mas eu agora sei mais sobre o português brasileiro e sobre as línguas em geral do que sabia quando comecei a investigação.

Contei essa história para mostrar que investigar o funcionamento de nossa língua é um projeto instigante e que o aprendizado e o ensino da língua portuguesa podem se tornar muito mais interessantes e amplos se vierem acompanhados da investigação. Da pesquisa. Pesquisar é uma forma organizada de tentar satisfazer nossa curiosidade natural. Ser um "investigador da língua" em maior ou menor grau é algo acessível a todos. A investigação do português não requer necessariamente tecnologias sofisticadas. Como ponto de partida bastam a curiosidade, o raciocínio analítico e a persistência.

A postura dogmática é muito comum em relação a nossa língua. O ensino de análise sintática é um exemplo típico dessa postura. A Sintaxe é o estudo da estrutura das sentenças. Em um sentido mais amplo é o estudo das estruturas possíveis para as línguas humanas. Como é possível que algo tão interessante se transforme, na maioria dos casos, em um exercício de adivinhação de "o que é que o professor quer que eu responda aqui?"

As perguntas interessantes não são feitas, não há espaço para a dúvida, para a investigação. Qual seria, por exemplo, o sujeito das sentenças (30) - (32)? Vocês não vão encontrar a resposta para essa questão em nenhuma gramática ou livro didático. Os livros didáticos e as gramáticas fazem de conta que esse tipo de sentença não existe. Fazem de conta que a noção de sujeito não apresenta problemas. ${ }^{26}$
Dá banana no sítio.
O sítio dá banana.
Lá era lindo!

A investigação científica nos faz tropeçar constantemente em surpresas. Uma revolução em nossa maneira de conceber o mundo aconteceu quando nos demos conta de que não era o Sol que girava em torno da Terra, mas sim a Terra que girava em torno do Sol.

Uma revolução também aconteceu dentro da Lógica e dos estudos lingüísticos quando se percebeu que a relação entre o sujeito e seu predicado que explica o significado de sentenças como (33) deve ser invertida se queremos entender o significado de sentenças quantificadas como (34). Em (33) estamos dizendo da pessoa designada pelo nome João que possui a propriedade de ser inteligente. O mesmo raciocínio não pode ser transposto para (34). Em (34) não estamos dizendo do ser nomeado pela expressão ninguém que ele é inteligente. A relação se dá no sentido inverso: estamos falando sobre a propriedade ser inteligente. Estamos afirmando dessa propriedade que não existe nenhum indivíduo ao qual ela possa ser atribuída. Essa descoberta permitiu a lógicos e lingüísticas entenderem o funcionamento de palavras como todo, algum e nenhum - os quantificadores. Essas palavras são responsáveis por operações lingüísticas paralelas a operações matemáticas. ${ }^{27}$

\footnotetext{
${ }^{26}$ Sobre essa questão, ver Pontes, E. 1986.

${ }^{27}$ Sobre os quantificadores ver uma introdução em de Swart 1998 e Chierchia 2003.
} 
João é inteligente

Ninguém é inteligente

Algumas descobertas podem ser bem-vindas. Por exemplo, uma descoberta que pode deixar contentes os defensores de que o Português brasileiro seja considerado uma língua distinta do Português Europeu é o fato de que o Português Brasileiro difere mais do Português Europeu do que, por exemplo, o Holandês difere do Alemão. ${ }^{28}$

Por outro lado, as pesquisas científicas podem nos levar a conclusões que num primeiro momento, não gostamos, ou não desejamos - conclusões que ameaçam nossas certezas. Um resultado das pesquisas sociolingüísticas que tem causado extremo desconforto é a descoberta de que não existe quem não faça "erros" de concordância verbal. Trata-se apenas de diferença percentual. ${ }^{29}$

No entanto, quando rejeitamos a ciência, abrimos mão de nossa capacidade de cuidar de nós mesmos e de nosso futuro. A solução de nossos problemas pessoais e sociais passa por sua compreensão. A sociedade atual está fortemente calcada na ciência e na tecnologia. Entretanto, são poucos os capazes de compreende-las. Essa questão é ainda mais aguda nos países subdesenvolvidos. Aqui grande número de pessoas sequer sabe ler e escrever. E, quando sabe, tem dificuldade em interpretar os textos mais complexos. $\mathrm{O}$ conhecimento se concentra nas mãos de poucas pessoas e de poucos países. Temos aí uma combinação perversa. A ignorância (principalmente sobre nós mesmos) leva à sedução pelo irracional e abre as portas ao preconceito, fanatismo e à manipulação fácil.

Posso dar um exemplo em relação a nosso conhecimento sobre a língua. Há muito os lingüistas sabem que não há línguas ou dialetos melhores ou piores que outros. ${ }^{30} \mathrm{O}$ valor que atribuímos a diferentes modos de falar é simplesmente cultural e ideológico. No entanto, um dos preconceitos mais fortes, continua sendo o preconceito lingüístico. Falar errado, continua sendo sinônimo de falta de inteligência. $\mathrm{O}$ medo de falar ou escrever "errado", ajuda a calar camadas inteiras da população. Ou seja, quem desconhece que sua linguagem vale tanto quanto qualquer outra, é muito mais facilmente calado.

Não podemos, portanto, abrir mão da produção e da divulgação do conhecimento em nossa área ou em qualquer outra. Para sermos capazes, enquanto nação, de escolher nosso caminho, precisamos entender a ciência mundial e sermos capazes de decidir sobre ela. Precisamos também ser capazes de perceber os perigos gerados por essa ciência. Para uma nação co tantos problemas mais imediatos como fome, doenças, desemprego, poluição... é fácil deixar a ciência e a pesquisa em segundo plano. No entanto, se fizermos isso abrimos mão de determinar nosso destino e até mesmo de solucionar nossos problemas mais básicos. Estamos inseridos num mundo no qual conhecimento é poder. E, num sentido ainda mais amplo, não podemos abrir mão de tentar esclarecer nossas questões mais profundas sobre quem somos e qual é nosso lugar no universo.

Uma outra razão para se ensinar e divulgar as descobertas da investigação científica em geral e o método científico é que a ciência, mais do que um corpo de conhecimentos é

\footnotetext{
${ }^{28}$ Sobre as diferenças entre o português brasileiro e o português europeu, ver Galves 2001 e Kato 2000.

${ }^{29}$ Ver aqui Scherre 1989.

${ }^{30}$ Para uma introdução às idéias básicas da sociolingüística, ver Fonseca \& Neves 1974.
} 
um modo de pensar. O modo científico de pensar é, ao mesmo tempo, criativo e disciplinado. É criativo porque pede soluções inovadoras e é disciplinador porque exige coerência com todo um saber já acumulado. Método científico inclui um mecanismo para a correção de seus próprios erros, através da exposição sistemática à confirmação e à crítica. Assim, ele nos estimula a pensar de modo independente, a desconfiar dos argumentos de autoridade. Esse modo de pensar é um legado essencial na formação do indivíduo e do cidadão. Trata-se de um jogo democrático, que nos obriga a debater e divulgar novas descobertas, a aceitar críticas e a considerar novos pontos de vista.

Vamos imaginar que eu já tenha terminado parte de meu trabalho sobre a genericidade no português brasileiro e queira apresenta-lo à comunidade acadêmica. Devo então apresenta-lo em reuniões científicas e submete-lo à publicação em revistas especializadas. Assim, exponho meu trabalho a críticas e sou obrigado a reformula-lo.

O método científico estimula a disciplina e a perseverança. Ele exige um diálogo rigoroso com estudos anteriores sobre o assunto investigado. Exige que a validade do raciocínio seja checada em detalhe pelo pesquisador e por seus pares. É necessária também a busca de evidências que apoiem as conclusões e a explicação de fatos que aparentemente as contradizem.

Mais um exemplo que envolve minha pesquisa sobre a genericidade. Uma questão que se coloca quando estudamos em maior profundidade algum aspecto de nossa língua é se o fenômeno se restringe ao português ou decorre de propriedades de todas as línguas humanas. Como eu disse anteriormente, pesquisadores divulgam e debatem suas idéias em encontros e revistas científicas. Num desses encontros assisti à comunicação de uma pesquisadora israelense sobre a diferença entre o uso no inglês dos dois tipos de sentenças genéricas exemplificados em (35) e (36) ${ }^{31}$ essas sentenças são semelhantes a sentenças do português que discutimos acima

'Cachorros tem quarto patas.'

A dog has four legs.

'Um cachorro tem quarto patas.'

Dogs have four legs.

Discutimos o assunto, ela me enviou seu trabalho e eu envie meu trabalho a ela. Vimos que o padrão 'generalização normativa' versus ' generalização descritiva' vale para as duas línguas. Valeria também para outras línguas mais distantes? Seria este um padrão universal? Como vocês vêem, o processo de troca de ideias se ampliem e envolvam cada vez mais pesquisadores. As chances de se entender melhor o fenômeno aumentam.

Ciência e educação científica são essências à sociedade e ao indivíduo. Cada um de nós pode ser, em maior ou em menor escala, um investigador. Assim podemos incorporar à nossa vida o prazer do conhecimento e da investigação. Trata-se de respeito a nós mesmos, a nossos alunos e à sociedade.

Como insiste Sagan em seu artigo, as descobertas científicas são gratificantes. Elas são uma celebração de nossa capacidade enquanto espécie. A ciência, como a arte, propõe

\footnotetext{
${ }^{31}$ Trata-se de Greenberg 2002.
} 
novas maneiras de se conceber o mundo, o universo e o nosso papel dentro dele. Uma bela teoria, uma correlação descoberta, é uma obra de arte e nos proporciona grande prazer.

\section{Referências}

CHIERCHIA, Gennaro 2003. Semântica. Campinas: EDUEL, UNICAMP.]

DE SWART 1998. Introduction to Natural Language Semantics. Stanford: CSLI.

FONSECA, Maria Stella V. \& NEVES, Moema F. 1974 (orgs.) Sociolinguística. Rio de Janeiro: Eldorado Tijuca.

GALVES, Charlotte 2001. Ensaios sobre as Gramáticas do Português. Campinas: UNICAMP.

GREENBERG, Yael 2002. Manifestations of Genericity. Ph.D. dissertation. Bar - Illan University, Israel.

KATO, Mary 2000. "The Partial Pro -Drop Nature and the Restricted VS order in Brazilien Portuguese”. In: KATO, Mary \& NEGRÃO, Esmeralda V. (eds.) Brazilian Portuguese and the Null Subject Parameter. Frankfurt: Vervuet IberoAmericana.

MÜLLER, Ana 2000. "Sentenças Genericamente Quantificadas e Expressões de Referência a Espécies no Português Brasileiro”. Cadernos de Estudos Lingüísticos 39: 141-158.

2000. "The Semantics of Generic Quantification in Brazilian Portuguese".

PROBUS 14. Berlin: de Gruyter: 279-298.

2003. “A Expressão da Genericidade nas Línguas Naturais”. In: Semântica Formal. São Paulo: Contexto: 153-172.

2003. "Tipos de Genericidade como Tipos de Modalidade". Revista Letras 60. Curitiba: UFPR: 341-362.

PONTES, Eunice S. L. 1986. Sujeito: da Sintaxe ao Discurso.São Paulo: Ática.

SCHERRE, Marta P. 1989. "Sobre a Atuação do Princípio da Saliência Fônica na Concordância Nominal". In: TARALLO, Fernando (org.) Fotografias Sociolinguísticas. Campinas: Pontes \& UNICAMP. 